Int. J. Odontostomat.,

12(3):205-210, 2018.

\title{
Williams-Beuren Syndrome: What Orthodontists Need to Know
}

\author{
Síndrome de Williams-Beuren: Lo que los Ortodoncistas Deben Saber
}

\begin{abstract}
Mariana Gonzaga Erthal Ribeiro'; Giordani Santos Silveira1; Vítor Francesconi Rodrigues; Mariele Cristina Garcia Pantuzo² \& Dauro Douglas Oliveira ${ }^{3}$
\end{abstract}

RIBEIRO, M. G. E.; SILVEIRA, G. S.; RODRIGUES, V. F.; PANTUZO, M. C. G. \& OLIVEIRA, D. D. Williams-Beuren syndrome: what orthodontists need to know. Int. J. Odontostomat., 12(3):205-210, 2018.

ABSTRACT: Williams-Beuren syndrome is a rare disease with manifestations such as cardiovascular changes, distinct facial features, mental retardation, and learning disabilities. Oral manifestations are not commonly described and can often be misdiagnosed. This report describes the case of a male patient diagnosed with Williams-Beuren syndrome presenting classic clinical features that affect the face as a convex profile, with maxillary protrusion and mandibular retrusion, a discreetly acute nasolabial angle, passive labial sealing, and an open mandibular angle characteristic of Class II skeletal pattern. In addition, the patient has oral manifestations such as the absence of some dental elements, a Class II of Angle 1st division, dental cross bite, and atresic arches. The periodontal condition presents with generalized gingivitis. Knowledge about the possible manifestations of Williams-Beuren syndrome is important to improve the ability of orthodontists to better serve these patients.

KEY WORDS: Williams-Beuren syndrome, oral manifestations, dental care, disabled persons, orthodontics.

\section{INTRODUCCIÓN}

Beuren et al. (1964) and Williams et al. (1961) described a clinical situation in which patients presented supravalvular aortic stenosis associated with a particular facial appearance and mental retardation. This congenital disorder, known as Williams Syndrome or Williams-Beuren Syndrome (WBS), results from a genetic alteration in the long arm of chromosome 7 (Ferrero et al., 2007; Nikitina et al., 2014). Once this spontaneous microdeletion of the genes occurs, the individual has an autosomal dominant hereditary pattern, with a $50 \%$ probability of transmission of this disorder to the offspring. Thus, the possibility of healthy parents having another child with WBS is small (Lashkari et al., 1999). The prevalence of WBS can vary from one in 7,500 (Strømme et al., 2002) to 25,000 (Yau et al., 2004) live births, but it might be even greater due to underdiagnosed cases (Kaplan et al., 2001). In addition, there is no distinction of prevalence between sex, race, and ethnicity (Hertzberg et al., 1994).
The clinical manifestations are multisystemic and can affect the cardiovascular, neurological, renal, visual, and auditory systems (Moskovitz et al., 2005). Most affected individuals have congenital heart defects, most often supravalvular aortic stenosis and peripheral pulmonary stenosis. Other very common signs include mental deficiency with delayed cognitive development, poor motor coordination, irritability (especially with loud sounds), hyperactivity, and anxiety. There are also records of renal dysfunction, hypertension, hypercalcemia, and reduced visual and auditory acuity (Williams et al.; Beuren et al.; Kaplan et al.; Moskovitz et al.).

The facial appearance - called the "gnome" or "elf" type, is characterized by a broad forehead, prominent ears, small nose with wide tip, depressed nasal bridge, long filter, increased inter-commissure distance, protruding lips, full cheeks, and small mento. In addition, there is a high prevalence of Class

\footnotetext{
${ }^{1}$ School of Dentistry, Pontifical Catholic University of Minas Gerais, Belo Horizonte, Brazil.

${ }^{2}$ Postdoctoral research fellow, School of Dentistry, Pontifical Catholic University of Minas Gerais, Belo Horizonte, Brazil.

${ }^{3}$ Program director of Orthodontics, Pontifical Catholic University of Minas Gerais, Belo Horizonte, Brazil.

This study was financed in part by the Coordenação de Aperfeiçoamento de Pessoal de Nível Superior - Brasil (CAPES) - Finance Code 001.
} 
II and III Angle malocclusions, increased mandibular plane, excessive interdental spaces, teeth hypoplasia, microdontia, dental agenesis, and macroglossia (Williams et al.; Beuren et al.; Kaplan; Moskovitz et al.; Yamaguchi et al., 2017).

A multidisciplinary follow-up is fundamental and, inevitably, an orthodontic evaluation is necessary, considering the risks involved by the presence of the systemic pathologies and the possibility that the correction of the malocclusion would represent in the quality of life of these patients. Surprisingly, the literature is poor (Habersack et al., 2007; Grecchi et al., 2011; Vieira et al., 2015; Yamaguchi et al.) regarding possible orthodontic interventions in patients with WBS.

Thus, this case report aims to describe and discuss the systematic craniofacial and dental aspects that should be considered in the orthodontic planning of a patient presenting WBS.

\section{CASE REPORT}

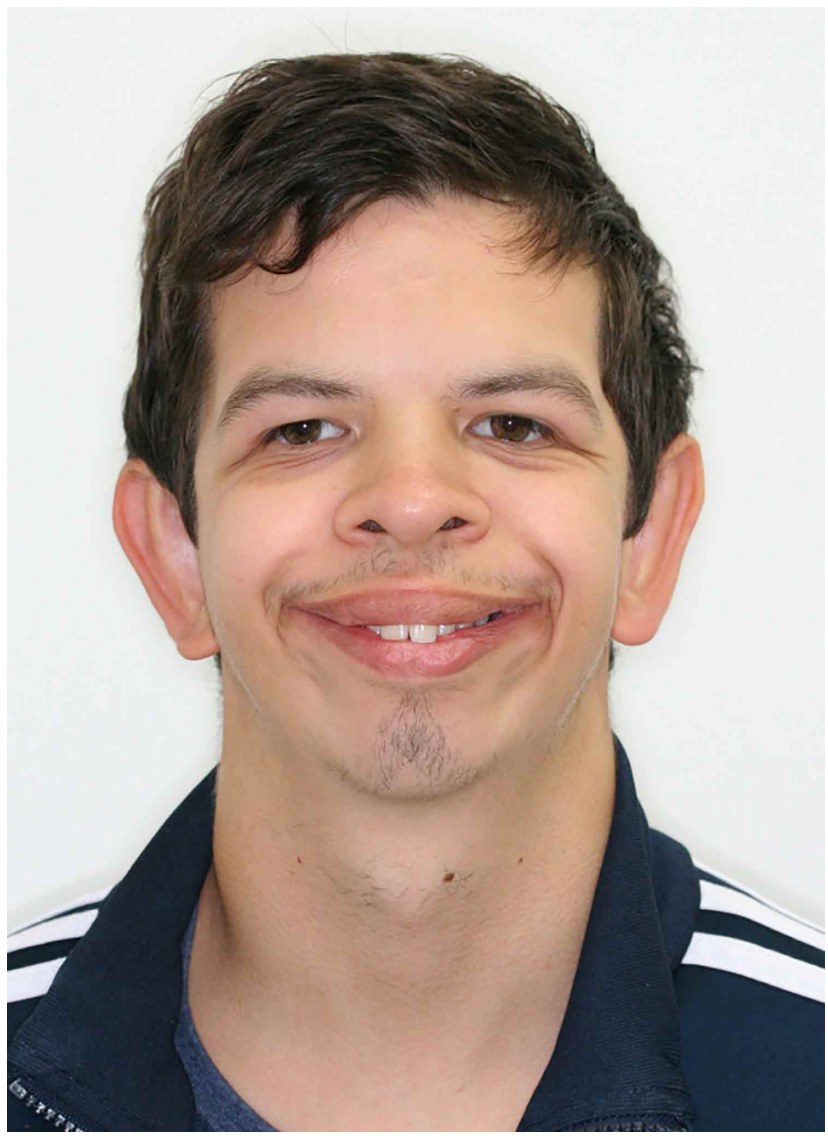

Fig. 1. Extraoral view in front - smilling.
A 20-year-old male patient leukoderma was accompanied by his parents to the Orthodontics Service of the Pontifical Catholic University of Minas Gerais to evaluate the feasibility of performing a treatment due to the failure of a previous orthodontic treatment.

During the anamnesis, his mother reported that the patient had WBS, confirmed by a genetic test, even though there was no history of cases of this syndrome in the family. Cardiac, blood pressure, renal, and visual changes had not been reported. The reported systemic alterations reported included hyper-calcemia and high cholesterol, intellectual deficit, high anxiety, low tolerance for frustration, irritability, and exaggerated sensitivity to loud sounds, but also cheerful and extroverted behavior.

Facial examination identified almost all WBSrelated features: broad forehead, prominent ears, small nose with broad tip, increased inter-commissure distance, bulging and protruding lips, full cheeks, small fingers, and much lower anterior facial height (Figs. 1, 2, and 3).

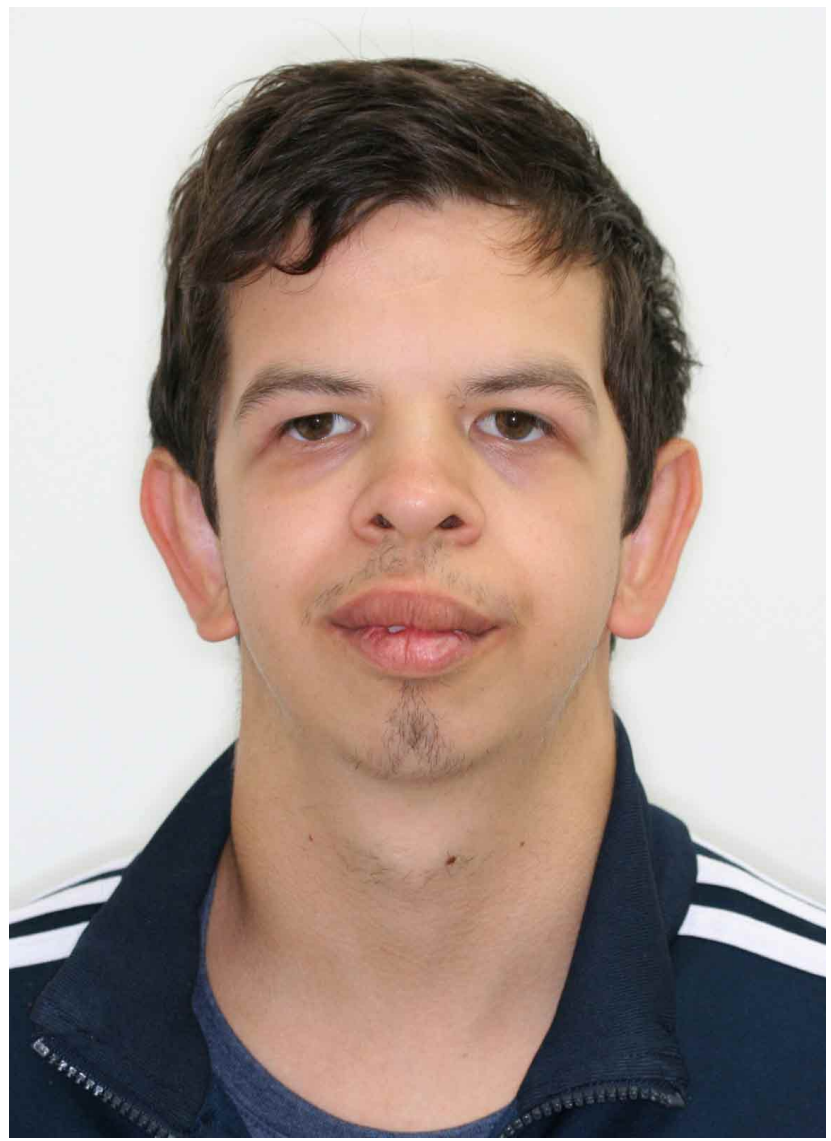

Fig. 2. Extraoral view in front - lips in rest. 


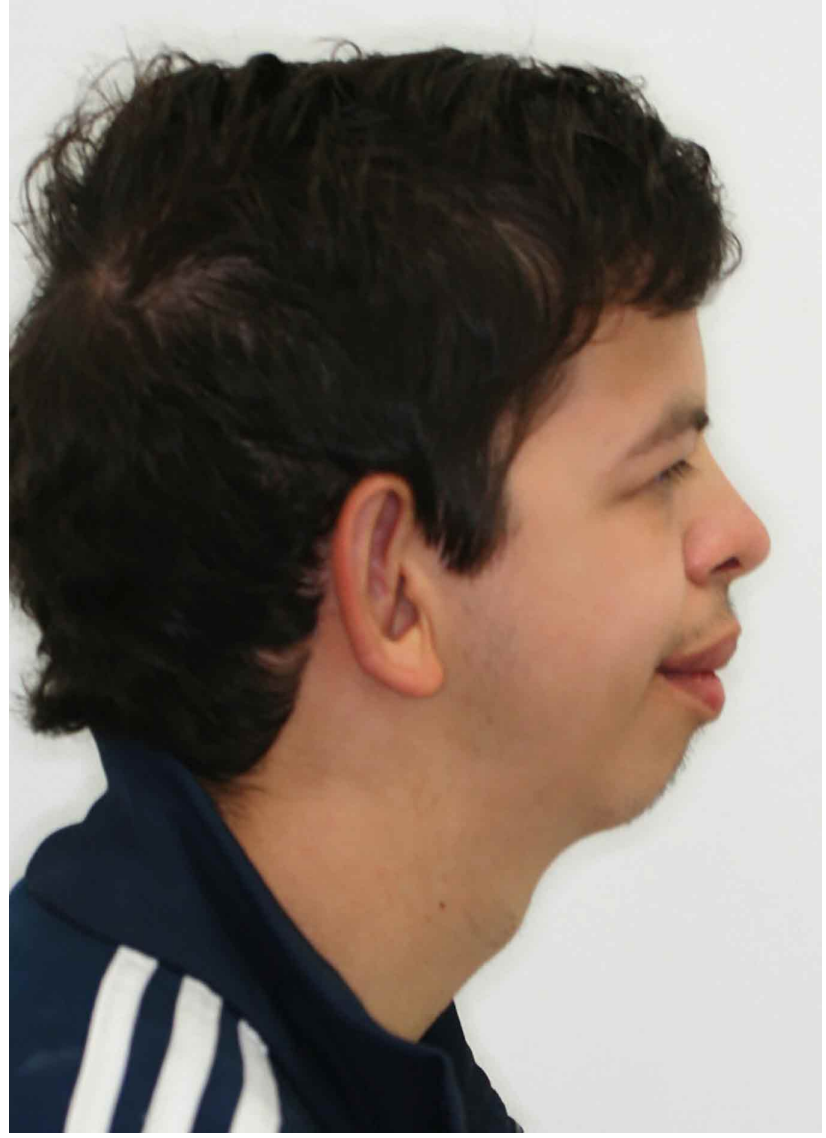

Fig 3. Extraoral view in profile.

The intra-oral evaluation revealed a mixed dentition stage with the presence of the canine and second molar upper deciduous of the right side and all lower deciduous molars, which were ankylosed. The unevenness in relation to the occlusal plane of these teeth contributed to the significant bilateral posterior open bite and pronounced Spee curve. In addition, the patient

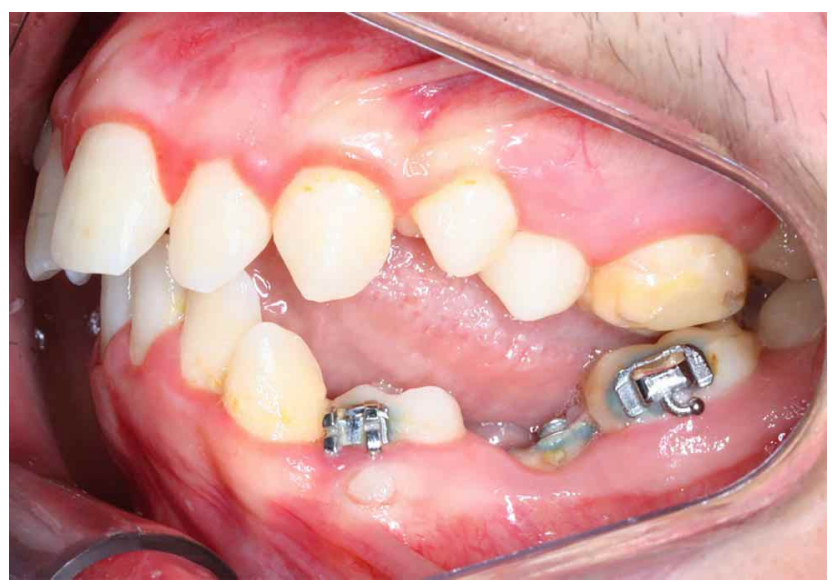

Fig. 4. Intraoral view. presented Angle Class II, 1st division with the lower middle line deviated $2 \mathrm{~mm}$ to the right, severely increased overjet $(6 \mathrm{~mm})$, and slightly increased overbite. Both dental arches were constricted transversely and with moderate crowding of $5 \mathrm{~mm}$, with emphasis on infravestibuloversion of the right upper canine. The first permanent molars presented enamel hypoplasia with distinct severity and orthodontic accessories, resulting from the failed attempt of a previous orthodontic treatment, which was bonded to the lower teeth of the left side. The periodontal condition presented with generalized gingivitis and the presence of macroglossia was not identified (Figs. 4, 5, 6, 7, and 8).

The panoramic radiograph confirmed the intraosseous presence of the second right upper premolar and the first lower premolars and the agenesis of the lower second premolars (Fig. 9). The teleradiography of the skull revealed a high mandibular plane with an almost nonexistent gonial angle compatible with the long face pattern (Fig. 10).

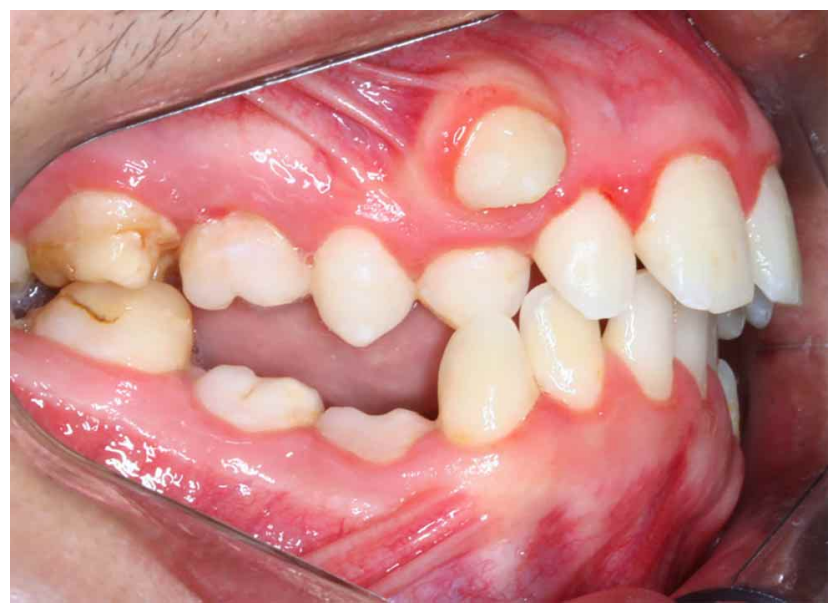

Fig. 5. Intraoral view.

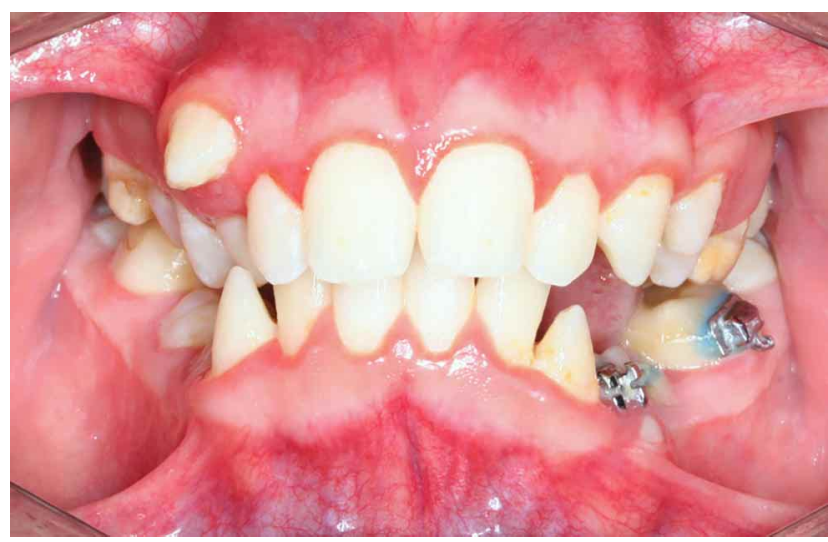

Fig. 6. Intraoral view. 


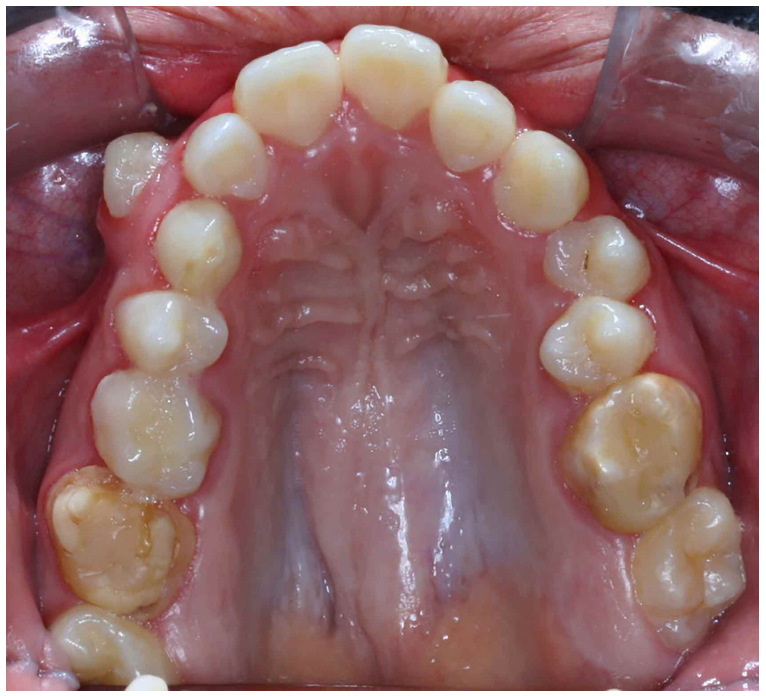

Fig. 7. Intraoral view.

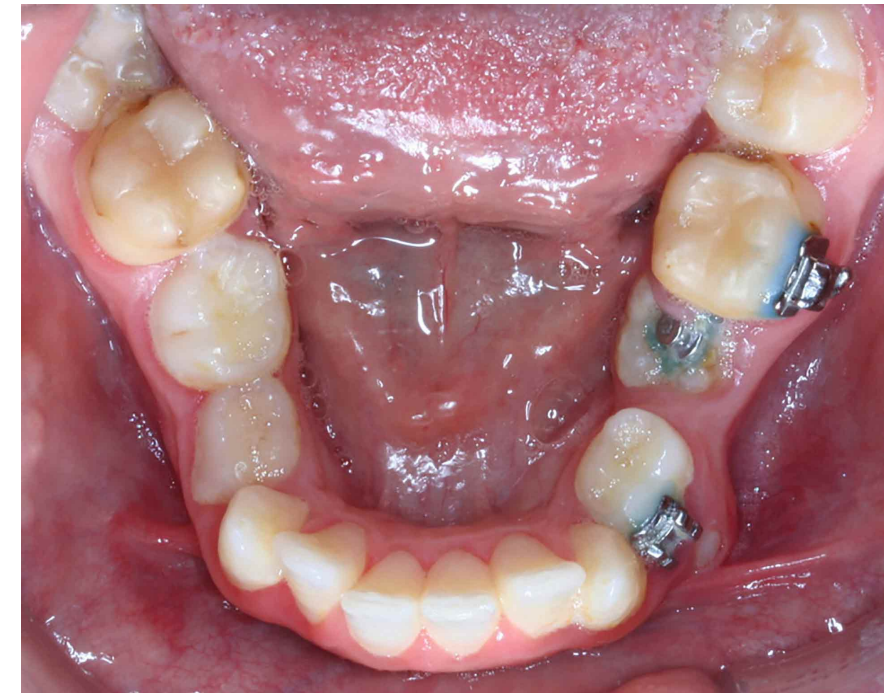

Fig. 8. Intraoral view.

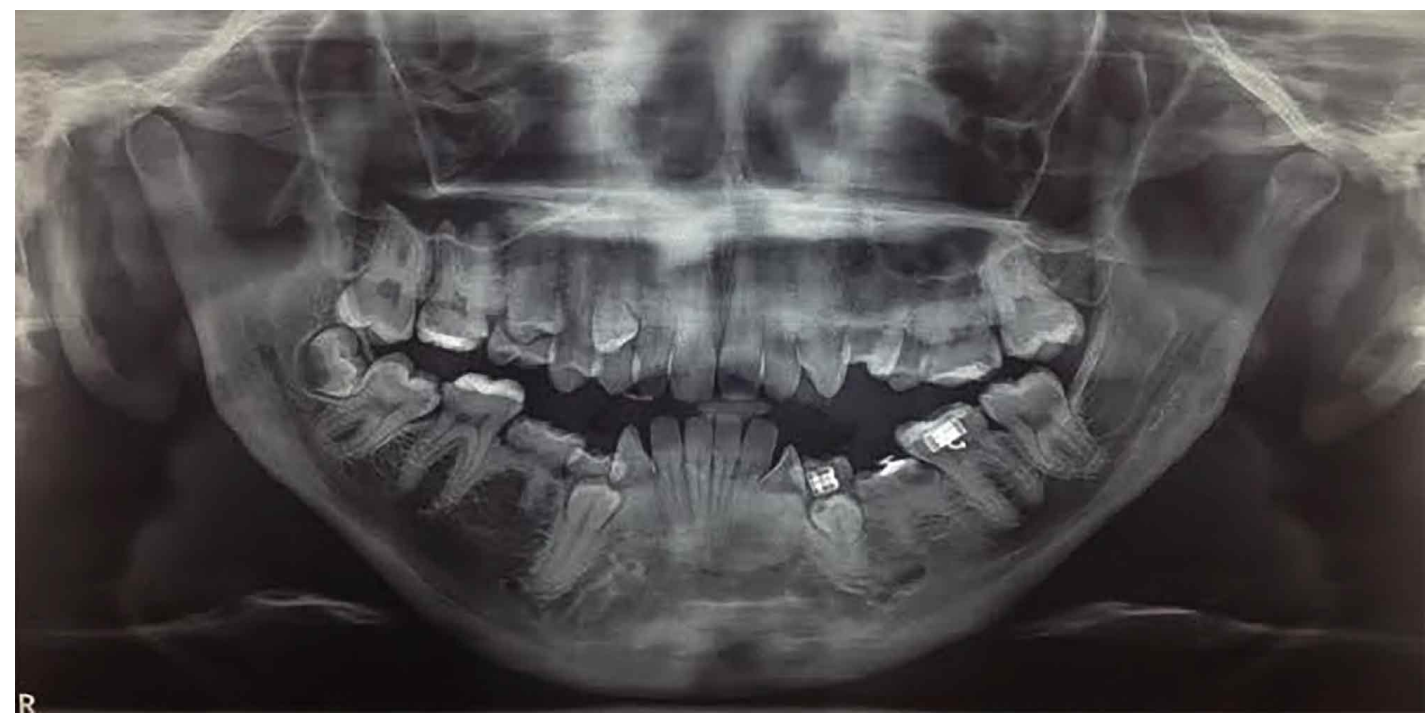

Fig 9. Panoramic radiograph.

\section{DISCUSSION}

According to the literature, the orthodontist usually receives a patient with the diagnosis of WBS defined, since many of the alterations present in this syndrome manifest from the first days of life or during infancy. Once the triad: facial type, mental retardation, and cardiopathy are identified, WBS is suspected, but the definitive diagnosis is only confirmed after the cytogenetic test called fluorescence in situ hybridization (Grecchi et al.). In the case reported here, no heart disease was found, but the facial characteristics and cognitive limitations observed in early childhood led the medical team to perform the genetic research that confirmed WBS.
Some articles describe the systemic, facial, and dentoalveolar findings of WBS, as well as genetic and epidemiological aspects (Williams et al.; Beuren et al.; Kaplan et al.; Axelsson et al., 2003; Moskovitz et al.; Wong et al., 2015). In the therapeutic field, basic medical and dental care are also discussed in the scientific literature. Publications regarding the planning and orthodontic treatment of WBS patients are scarce. In the bibliographic research performed here, only three case reports (Habersack et al.; Grecchi et al.; Vieira et al.) were found discussing ortho-surgical treatment in patients with WBS. What is surprising is the 


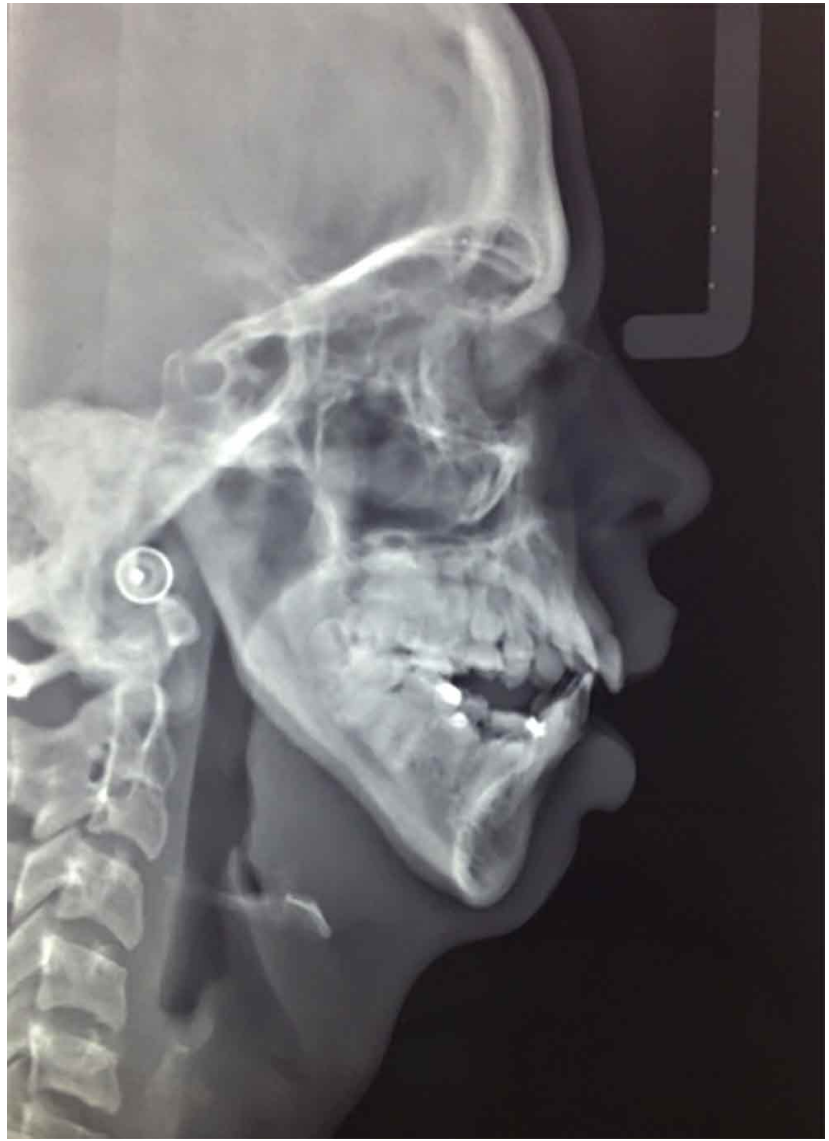

Fig 10. Cephalometric radiograph.

incompatibility found between severity and the extent of craniofacial and dentoalveolar changes found in this syndrome that obviously require orthodontic correction, as well as the little attention given by the scientific community to this topic.

Orthodontic planning involves careful evaluation of four areas: (1) severity of systemic changes, (2) extent of maxillo-mandibular deviations, (3) shape and number of dental anomalies, and (4) periodontal condition.

Systemic alterations. Supravalvular aortic stenosis and peripheral pulmonary stenosis are the most common pathologies in patients with this syndrome and inspire more care from the medical-dental team. As a preventive measure of cardiac complications resulting from transient bacteremia, antibiotic therapy prior to clinical dental procedures is indispensable (Williams et al.; Beuren et al.; Kaplan et al.; Moskovitz et al.).

Orthognathic surgery may be a high-risk procedure for these patients, not only for possible cardiac changes, but also for renal impairment and hypercalcemia. Contraindication can be real and blunt.
The orthodontist's role is to adapt therapeutic goals within a biological cost-benefit relationship that prioritizes appropriate function and aesthetics to the detriment of ideal goals.

Maxillo-mandibular deviations. The anterior slope of the maxilla, the anterior deficiency of the middle third of the face, the increased mandibular plane, and the long face pattern are the maxillo-mandibular changes most commonly found in WBS. The open bite may be present or not, and if it is associated with macroglossia, its extent may be wide (Williams et al.; Beuren et al.; Kaplan et al.; Axelsson et al.; Moskovitz et al.; Wong et al.). The correction of these deviations is due to the limitations imposed by the systemic factors mentioned above, mainly due to the need for bimaxillary surgeries and because these present higher morbidity.

Dental anomalies of shape and number. Form and number abnormalities are frequently observed in patients with this syndrome. Enamel hypoplasia of varying severity between individuals and between teeth of the same patient, anatomical simplification of the incisors, bud-shaped mandibular molars, and microdontia are also reported (Williams et al.; Beuren et al.; Kaplan et al.; Axelsson et al.; Moskovitz et al.; Wong et al.). Dental or hypodontia are present in $11 \%$ of individuals with WBS, and the orthodontist needs to evaluate, with the medical and dental team, the best treatment option: either orthodontic space closure or prosthetic implant replacement.

Periodontal condition. Most affected individuals present some degree of mental retardation and motor difficulty, so dental and periodontal health may be compromised. The control of hygiene should be reinforced with an adequate and more frequent oral hygiene protocol to reduce the chances of development of carious lesions and periodontal problems in WBS patients (Axelsson et al.; Wong et al.).

In the patient described here, the absence of cardiopathies, arterial hypertension, and renal impairment allows the option of orthognathic surgery in the context of orthodontic treatment. The dentoalveolar extrusion present in the anterior segment of the mandible compensates vertically for the excess of the basal vertical growth of the mandible, and therefore the anterior open bite is not observed. In the posterior segments of the mandible, vertical dentoalveolar development did not occur due to ankylosis of the lower deciduous molars, contributing to the establishment of a significant posterior open bite bilaterally. 


\section{CONCLUSION}

The craniofacial and dentoalveolar abnormalities most commonly presented by WBS patients require orthodontic correction and are often associated with orthognathic surgery.

The indication of the skeletal correction with involvement of this surgical procedure can be limited by the severity of the systemic alterations, mainly in the cardiovascular and renal systems.

Even considering orthodontic treatment alone, one should not overlook the patient's motor limitations that may compromise oral hygiene.

Likewise, negative behavioral characteristics such as irritability, anxiety, and hyperactivity, when present, can increase significantly with the pain and discomfort caused by orthodontic appliances.

Finally, orthodontic planning and treatment must be performed in conjunction with the medical and dental team.

RIBEIRO, M. G. E.; SILVEIRA, G. S.; RODRIGUES, V. F.; PANTUZO, M. C. G. \& OLIVEIRA, D. D. Síndrome de WilliamsBeuren: Lo que los ortodoncistas deben saber. Int. J. Odontostomat., 12(3):2015-210, 2018.

RESUMEN: El síndrome de Williams-Beuren es una enfermedad rara con manifestaciones tales como cambios cardiovasculares, diversas características faciales, retraso mental y problemas de aprendizaje. Las manifestaciones orales no se describen comúnmente y con frecuencia se pueden diagnosticar erróneamente. Este informe describe el caso de un paciente masculino diagnosticado con síndrome de Williams-Beuren que presentaba características clínicas clásicas que afectaban la cara como un perfil convexo, con protrusión maxilar y retrusión mandibular, un ángulo nasolabial discretamente agudo, sellado labial pasivo y un ángulo mandibular abierto característico del patrón esquelético clase II. Además, el paciente presentaba manifestaciones orales tales como, ausencia de algunos elementos dentales, una clase II de Angle $1^{\text {a }}$ división, mordida dental cruzada y arcos acrílicos. La condición periodontal se presentaba con gingivitis generalizada. El conocimiento sobre las posibles manifestaciones del síndrome de Williams-Beuren es importante ya que mejora la capacidad de los ortodoncistas para atender mejor a estos pacientes.

PALABRAS CLAVE: Síndrome de Williams, manifestaciones orales, cuidado dental, personas discapacitadas, ortodoncia.

\section{REFERENCES}

Axelsson, S.; Bjørnland, T.; Kjaer, I.; Heiberg, A. \& Storhaug, K. Dental characteristics in Williams syndrome: a clinical and radiographic evaluation. Acta Odontol. Scand., 61(3):129-36, 2003.

Beuren, A. J.; Schulze, C.; Eberle, P.; Harmjanz, D. \& Apitz, J. The syndrome of supravalvular aortic stenosis, peripheral pulmonary stenosis, mental retardation and similar facial appearance. Am. J. Cardiol., 13(4):47183, 1964

Ferrero, G. B.; Biamino, E.; Sorasio, L.; Banaudi, E.; Peruzzi, L.; Forzano, S.; Di Cantogno, L. V. \& Silengo, M. C. Presenting phenotype and clinical evaluation in a cohort of 22 Williams-Beuren syndrome patients. Eur. J. Med. Genet., 50(5):327-37, 2007.

Grecchi, F.; Zollino, I.; Perrotti, V. \& Carinci, F. Williams-Beuren Syndrome treated with orthognathic surgery and combined partial glossectomy: case report. J. Osseointegration, 3(2):91-4, 2011.

Habersack, K.; Grimaldi, B. \& Paulus, G. W. Orthodontic orthognathic surgical treatment of a subject with Williams Beuren syndrome a followup from 8 to 25 years of age. Eur. J. Orthod., 29(4):332-7, 2007.

Hertzberg, J.; Nakisbendi, L.; Needleman, H. L. \& Pober, B. Williams syndrome--oral presentation of 45 cases. Pediatr. Dent., 16(4):262-7, 1994.

Kaplan, P.; Wang, P. P. \& Francke, U. Williams (Williams Beuren) syndrome: a distinct neurobehavioral disorder. J. Child Neurol., 16(3):177-90, 2001.

Lashkari, A.; Smith, A. K. \& Graham, J. M. Jr. Williams-Beuren syndrome: an update and review for the primary physician. Clin. Pediatr. (Phila.), 38(4):189-208, 1999.

Moskovitz, M.; Brener, D.; Faibis, S. \& Peretz, B. Medical considerations in dental treatment of children with Williams syndrome. Oral Surg. Oral Med. Oral Pathol. Oral Radiol. Endod., 99(5):573-80, 2005.

Nikitina, E. A.; Medvedeva, A. V.; Zakharov, G. A. \& Savvateeva-Popova, E. V. Williams syndrome as a model for elucidation of the pathway genes - the brain - cognitive functions: genetics and epigenetics. Acta Naturae, 6(1):9-22, 2014

Strømme, P.; Bjørnstad, P. G. \& Ramstad, K. Prevalence estimation of Williams syndrome. J. Child Neurol., 17(4):269-71, 2002.

Vieira, G. M.; Franco, E. J.; da Rocha, D. F.; de Oliveira, L. A. \& Amorim, R. F. Alternative treatment for open bite Class III malocclusion in a child with Williams-Beuren syndrome. Dental Press J. Orthod., 20(1):97107, 2015.

Williams, J. C.; Barratt-Boyes, B. G. \& Lowe, J. B. Supravalvular aortic stenosis. Circulation, 24:1311-8, 1961.

Wong, D.; Ramachandra, S. S. \& Singh, A. K. Dental management of patient with Williams Syndrome - A case report. Contemp. Clin. Dent., 6(3):41820, 2015

Yamaguchi, T.; Shirota, T.; Adel, M.; Takahashi, M.; Haga, S.; Nagahama, R.; Nakashima, M.; Furuhata, M.; Kamatani, T. \& Maki, K. Orthodontic treatment and maxillary anterior segmental distraction osteogenesis of a subject with Williams-Beuren Syndrome and isolated cleft palate: A long-term follow-up from the age of 5 to 24 years. Case Rep. Dent., 2017:7019045, 2017.

Yau, E. K.; Lo, I. F. \& Lam, S. T. Williams-Beuren syndrome in the Hong Kong Chinese population: retrospective study. Hong Kong Med. J., 10(1):22-7, 2004.

Corresponding author:

Mariele Cristina Garcia Pantuzo

Av. Dom José Gaspar, 500, Prédio 46, Sala 106

Belo Horizonte, MG, 30535-610

BRASIL

E-mail: marielegarcia@yahoo.com.br

Received: 23-02-2018

Accepted: 07-06-2018 